\title{
Correction to: Who ate my chocolate? Small mammals and fruit damage in cacao agroforestry
}

\author{
Camila Righetto Cassano (i) Vanessa Araújo Rios • Fernanda Amato Gaiotto $\mathbb{C}$
}

Published online: 4 August 2021

(C) Springer Nature B.V. 2021

\section{Correction to: Agroforest Syst}

https://doi.org/10.1007/s10457-021-00645-3

In the original publication of the article, the reference and the citation for Mariadoss et al. (2020) was incorrectly published without the first author name. The correct citation and the reference is given with this Correction.

The correct citation has been changed from Alice and Chakraborty (2020) to Mariadoss et al. (2020).

The original article has been corrected.

\section{Reference}

Mariadoss A, Alice J, Chakraborty A (2020) Rodent damages and approaches for their management. Innov Farm 5:54-59

Publisher's Note Springer Nature remains neutral with regard to jurisdictional claims in published maps and institutional affiliations.

The original article can be found online at https://doi.org/10.1007/s10457-021-00645-3.

C. R. Cassano $(\bowtie) \cdot$ F. A. Gaiotto

Laboratório de Ecologia Aplicada à Conservação, Universidade Estadual de Santa Cruz, Rodovia Jorge

Amado km 16, Ilhéus, BA 45662-900, Brazil

e-mail: crc.uesc@gmail.com

\section{F. A. Gaiotto}

e-mail: gaiotto@uesc.br

V. A. Rios

Programa de Pós-Graduação Em Zoologia, Universidade Estadual de Santa Cruz, Rodovia Jorge Amado km 16, Ilhéus, BA 45662-900, Brazil

e-mail: vanessarios.bio@gmail.com 